\title{
Further Validation of Slovak Big Five Inventory-2: Six-Months Test-Retest Stability and Predictive Power
}

\author{
Michal Kohút (iD) , Veronika Kohútová (D) , Peter Žitný (D) , Peter Halama (i) \\ Department of Psychology, Faculty of Arts, University of Trnava, Hornopotočná 23, 91843 Trnava, Slovak Republic
}

\begin{abstract}
The current study focuses on exploring the 6-month test-retest stability of the Slovak second version of the Big Five Inventory (BFI-2) and its predictive power for subjective and psychological well-being, on value-focused behavior and everyday behavior. The sample consisted of 414 adult Slovak participants, who reported on their personalities using the BFI- 2 on the first occasion, and then again circa 6 months later, along with well-being and behavior self-report measures focused on the past 6 months. The results showed a strong test-retest stability of the Slovak BFI-2's domains and facets. The Slovak BFI-2 also showed the expected pattern of well-being predictions with Extraversion and Negative Emotionality domains as the strongest predictors. Furthermore, meaningful trait-behavior links of the Slovak BFI-2 were discovered. Overall, our results contribute to the robust international knowledge base regarding stability, predictive power and ecological validity of the Big Five personality factors.
\end{abstract}

Key words: BFI-2, test-retest stability, predictive power, well-being, ecological validity

\section{Introduction}

Recently, Soto and John (2017) introduced a new personality scale, Big Five Inventory-2 (BFI-2), which is a revised and extended version of the BFI (John, Srivastava, 1999). Similarly to $\mathrm{BFI}$, the BFI-2 has key characteristics - focus, clarity, and brevity. It captures prototypical characteristics of each Big Five domain, using easy statements and it is short enough to be completed within 10 minutes. It consists of 5 domains and 3 facets per domain, namely Extraversion (Sociability, Assertiveness, Energy Level), Agreeableness (Compassion, Respectfulness, Trust), Conscientiousness (Organization, Productiveness, Responsibility), Negative Emotionality (Anxiety, Depression, Emotional Volatility) and Open-Mindedness (Intellectual Curiosity, Aesthetic Sensitivity, Creative Imagination). It provides breadth and efficiency and high bandwidth on the do-

Correspondence concerning this article should be addressed to Michal Kohút, Department of Psychology, Faculty of Arts, University of Trnava, Hornopotočná 23, 91843 Trnava, Slovak Republic.

E-mail: michal.kohut@truni.sk

Received December 5, 2019

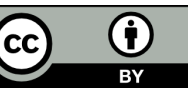


main level and descriptive and predictive precision of high fidelity on the facets level (Soto \& John, 2017).

In the recent past, this measurement was adopted, among others, in German (Danner et al., 2019), Dutch (Denissen, Geenen, Soto, John, \& van Aken, 2020), Russian (Shchebetenko, Kalugin, Mishkevich, Soto, \& John, 2020) as well as in the Slovak language (Halama, Kohút, Soto, \& John, 2020). The Slovak BFI-2 adaptation shows very good internal consistency on the domain level and, from lower to higher variation of internal consistency, on the facet level, which is acceptable due to the number of items. The Slovak BFI-2 retains the intended structure at the domain and facet levels. The principal component analysis of facets recovered the intended BFI-2 structure. The hierarchical structure of the Slovak BFI-2 is similar in robustness to the original English version. The Slovak BFI-2 was validated by association with gender and age, where it confirmed similar differences as those obtained in the previous Big Five research and original English version. It was further validated by association with the NEO-FFI and TIPI, where it showed good convergence. Finally, the validation was done using association with selected well-being measures and it shows a meaningful pattern of associations at both domain and facet levels (Halama et al., 2020).

Further examination of the Slovak BFI-2 is needed to ensure its capacity to predict real-life consequences and to serve as a useful tool for measurement of personality traits. Soto and John (2017) verified 2-month test-retest stability, where the average 2-month stability was .76 at the domain level and .73 at the facet level, thus showing clear evidence of factorial validity. Test-retest stability was done on other Big Five instruments. For example, 2-month test-retest validation of Italian BFI shows good stability, with all correlations be- ing higher than .75 (Fossati, Borroni, Marchione, \& Maffei, 2011), and 6-week test-retest in a German sample of BFI shows average correlations of .78 (Rammstedt \& Danner, 2017). The meta-analysis of test-retest stability of different Big Five measures estimated median aggregated scores for Big Five traits at .816. The most dependable scores were found for Extraversion, while less dependable were identified for Agreeableness (Gnambs, 2014). As the Big Five measures appear to have good test-retest stability, we want to confirm and report the 6-month test-retest stability of Slovak BFI-2.

Big Five domains have been robustly connected to well-being variables, both subjective and psychological ones. The relationship between psychological well-being (PWB) and personality is at a moderate level (Grant, Langan-Fox, \& Anglim, 2009). The highest correlations are shown between general PWB and Neuroticism, Conscientiousness and Extraversion (Hicks \& Mehta, 2018). Psychological and subjective well-being correlates positively with Extraversion and Conscientiousness and negatively with Neuroticism (Reyes, Shmotkin, \& Ryff, 2002). These results were confirmed by Kokko, Tolvanen, and Pulkkinen (2013), who stated a high negative relationship with Neuroticism and a positive one with Extraversion. They also identified the relationship between PWB and Conscientiousness, Openness to experience and Agreeableness. All the factors of Big Five personality together explain $68-74 \%$ of variance of Environmental mastery; $63-66 \%$ of Self-acceptation; $55-62 \%$ of Purpose in life; $50-73 \%$ of Positive relations; $51-56 \%$ of Personal growth and $36-51 \%$ of Autonomy (Anglim \& Grant, 2016; Sun, Kaufman, \& Smillie, 2018). Specifically, positive relations were predicted by Extraversion and Agreeableness in a positive way and by Neuroticism in a negative way. Autonomy was negatively predicted by Neuroticism and 
Agreeableness and positively by Openness to experience. Environmental mastery was negatively predicted by Neuroticism and by Conscientiousness and Extraversion in a positive way. Personal growth was positively predicted by Openness to experience, Conscientiousness, and Extraversion. Purpose in life was mainly predicted by Conscientiousness and Extraversion and, to a lower extent, positively by Openness to experience and negatively by Neuroticism. Self-acceptation was mainly predicted by Neuroticism in a negative way and by Extraversion and Conscientiousness in a positive way (Anglim \& Grant, 2016). The cognitive factor of subjective well-being - satisfaction with life shows strongest associations with Neuroticism in a negative way and with Extraversion in a positive one. Smaller correlations were also found with Agreeableness and Conscientiousness (Stolarski \& Matthews, 2016; Balgiu, 2019). Extraversion and Neuroticism were found to be strong predictors of life satisfaction, but the depression scale was sufficient for predicting the facets of Neuroticism (Schimmack et al., 2004). The great amount of confirmed associations among Big Five and well-being domains allows us to use this construct for convergent validation of the BFI-2.

In our validation process, we were inspired by Soto and John (2017) in their focus on behavioral measures, based on Schwartz's theory of value system. They found that each behavioral criterion was significantly predicted by at least one domain and facet. Furthermore, each criterion was associated with distinctive and conceptually meaningful set of predictors. For example, benevolent behavior was predicted most strongly by Agreeableness, namely by Compassion and Trust. Hedonistic behavior was predicted most strongly by low level of Conscientiousness, specifically low Productiveness and Responsibility. Self-directed behavior was mainly predicted by Open-mindedness, and, on the facet level, by Intellectual curiosity and Creative imagination. In order to expand the knowledge on the Big Five personality traits in Slovakia and to inform about ecological validity of the BFI-2, we included the investigation of how the Big Five traits predict common or "daily" behavioral acts in this study. The item selection was inspired by Chapman and Goldberg (2017). They found the association of Extraversion with drinking in a bar, going running or planning a party. For Agreeableness, they found correlations with behavior that benefits others, like ironing, washing dishes and so on. For Emotional stability, the low levels were associated with taking tranquilizing pills, drinking alcohol or having more nightmares. Open-mindedness correlated, for example, with daydreaming, meditating, attending art-exhibitions or trying something completely new.

To sum up, we focused on 3 areas that have not yet been investigated for Slovak BFI-2 either specifically or more generally in the Big Five approach to personality in Slovakia. The first goal was aimed at the question of how stable the Big Five factors in Slovakia were. To answer this, we investigated the test-retest stability of BFI-2 domains and facets in a 6-month period. The second goal focused on the predictive power of Slovak BFI-2 for subjective and psychological well-being and behavioral measures of values in a 6-month period. This allowed us to compare our results with other studies focused on this area and to further validate the Slovak BFI-2. The third goal was aimed at expanding the Slovak knowledge of Big Five factors that was also supposed to provide us with a perspective in relation to the ecological validity of the Slovak $\mathrm{BFI}-2$. In this regard, we inspected whether the BFI-2 domains could predict some of the mundane or "everyday" behavioral acts connected to Big Five factors in a 6-month period. 


\section{Methods}

\section{Sample}

The sample for this study was collected on two separate occasions. The first data collection was in late 2018 and the second was circa 6 months later. The participants were recruited through an online panel of research agency. Every participant agreed through the informed consent. Only participants that passed multiple attention check questions remained in the final sample. The first sample was collected for the purpose of validation of Slovak short and extra short BFI-2 versions (Kohút, Halama, Soto, \& John, submitted). This sample consisted of 801 participants, who successfully completed the survey. The research agency then randomly invited circa half of the sample for the second occasion. The final sample used in this study consists of 414 adults, aged between 18 and 75 years $(M=46.23, S D=14.36) .239(57.7 \%)$ were male with a mean age of $45.03(S D=13.87)$ and 175 (42.3\%) were female with a mean age of $47.86(S D=14.89)$. Participants were compensated for their participation by small credits that could be exchanged for different products.

\section{Measures}

The current study is focused on further validation of the Slovak version of Big Five Inventory 2 (Halama, Kohút, Soto, \& John, 2020; see Soto \& John, 2017 for the original version). This inventory consists of sixty 5-point scales focused on accessing 5 personality domains and 15 facets: Extraversion (Sociability, Assertiveness, Energy Level), Agreeableness (Compassion, Respectfulness, Trust), Conscientiousness (Organization, Productiveness, Responsibility), Negative Emotionality
(Anxiety, Depression, Emotional Volatility) and Open-Mindedness (Aesthetic Sensitivity, Intellectual Curiosity, Creative Imagination). Participants completed this inventory on both occasions. Cronbach's alpha for the first/second occasion was .79/.78 for Extraversion, $.79 / .80$ for Agreeableness, .84/.85 for Conscientiousness, $.87 / .89$ for Negative Emotionality and .80/.83 for Open-Mindedness. Internal consistency for the facets was understandably lower due to lower number of items, ranging between .46 (Assertiveness) and .76 (Aesthetic Sensitivity) for the first occasion ( $M=$ $.65)$, and between .51 (Assertiveness) and .79 (Aesthetic Sensitivity) for the retest ( $M=.68$ ).

During the second occasion, we assessed participants' subjective and psychological well-being, on value-oriented behavior and some of their everyday behavior in the last 6 months.

Subjective well-being was assessed using Satisfaction with Life Scale (SWLS; Diener, Emmons, Larsen, \& Griffin; 1985), which is a 5 -item scale focused on measuring global satisfaction with life using a 7-point scale. Items were translated to Slovak from the original version by two of the authors. Cronbach's alpha for this scale was .90.

Ryff's 42-item Psychological Wellbeing Scale (Ryff et al., 2010; Ryff, 1989) was used to assess the participants' psychological well-being. This scale focuses on six areas of psychological well-being using seven 7-point scales for each area. Items were translated to Slovak from the original version by two of the authors. Internal consistency was adequate: .71 for Autonomy subscale, .62 for Environmental mastery subscale, .69 for Personal growth subscale, .77 for Positive relations with others subscale, .70 for Purpose in life subscale and .82 for Self-acceptance subscale.

The use of behavioral self-reports was inspired by the original BFI-2 adaptation and validation study by Soto and John (2017). We used 40 items selected from Bardi and 
Schwartz's (2003) 80-item scale to assess behavior oriented on conformity (e.g., "Avoid arguments so that others won't be angry with me"), tradition (e.g., "Show modesty with regard to my achievements and talents"), benevolence (e.g., "Do my friends and family favours without being asked"), power (e.g., "Manipulate others to get what I want"), universalism (e.g., "Show my objections to prejudice - e.g., against racial groups, the homeless"), hedonism (e.g., "Indulge myself by buying things that I don't really need"), security (e.g., "Avoid dangerous places and neighbourhoods"), stimulation (e.g., "Look for new people to meet"), achievement (e.g., "Take on many commitments"), and self-direction (e.g., "Make my own decisions"). These items were selected and translated into Slovak by two of the authors. We asked participants to judge how frequently they behaved in the way described in these items in the last 6 months, using a 5-point scale ranging from I have never behaved this way to I behaved this way every time I had a chance. Internal consistency of these scales ranged from low to adequate $(M=.51)$, bearing in mind the low number of items (4 per scale) and width of the measured constructs, varying between .19 (Conformity) and .76 (Power).

To assess the frequency of various everyday behaviors, we asked the participants to indicate how many times they had engaged in these activities in the last 6 months using the scale ranging from never and continuing with once or twice, up to 5 times, 6 to 10 times, 11 to 15 times and more than 15 times. We asked about 33 activities including culture (e.g., "visiting exhibition or gallery"), relaxing (e.g. "meditating"), sports ("went running") and others (e.g., "crying", "tried something new", "forgot something important"). These were inspired by the signature behaviors of the Big Five study by Chapman and Goldberg (2017).

\section{Results}

Table 1 presents descriptive statistics, 6-month test-retest stability, gender differences of BFI2 domains and facets. It is apparent that, the test-retest stability of domains is quite good, ranging between .76 (58\% of the explained variance) and .83 (69\%). For the facets, stability varied from .59 (Compassion) to .82 (Sociability), averaging at .70, indicating satisfactory stability over the 6-month period. Statistically significant change was detected in 3 facets, but this difference is negligible to small in terms of the effect size. Comparing females and males, the stability is quite similar for both genders, although overall slightly better for males. Significant gender differences were found in Agreeableness and Negative Emotionality domains, in which females scored higher. These differences are small to medium. Moreover, evaluating stability, the gender differences in domains and facets are fairly similar on both time points. These gender differences differed only by .13 at most, averaging at .05 in absolute value of Cohen's $d$.

To explore the power of the BFI-2 domains to predict satisfaction with life, psychological well-being and value-oriented behavior, we tested hierarchical linear regression models, which consisted of gender and age in the first step and all 5 domains in the second step. All independent variables were entered simultaneously. Exploring the predictive power of the BFI-2 facets, we entered gender and age in the first step and then entered 15 facets using the forward selection method with $p<.05$ inclusion criterion. Gender and age variables were added to these models to control for shared covariance between constructs and to better reflect the explained variance by BFI-2 not explained by gender or age. All models were checked and they passed assumptions of linear regression (Durbin-Watson, collinearity statistics, multidimensional outliers, 


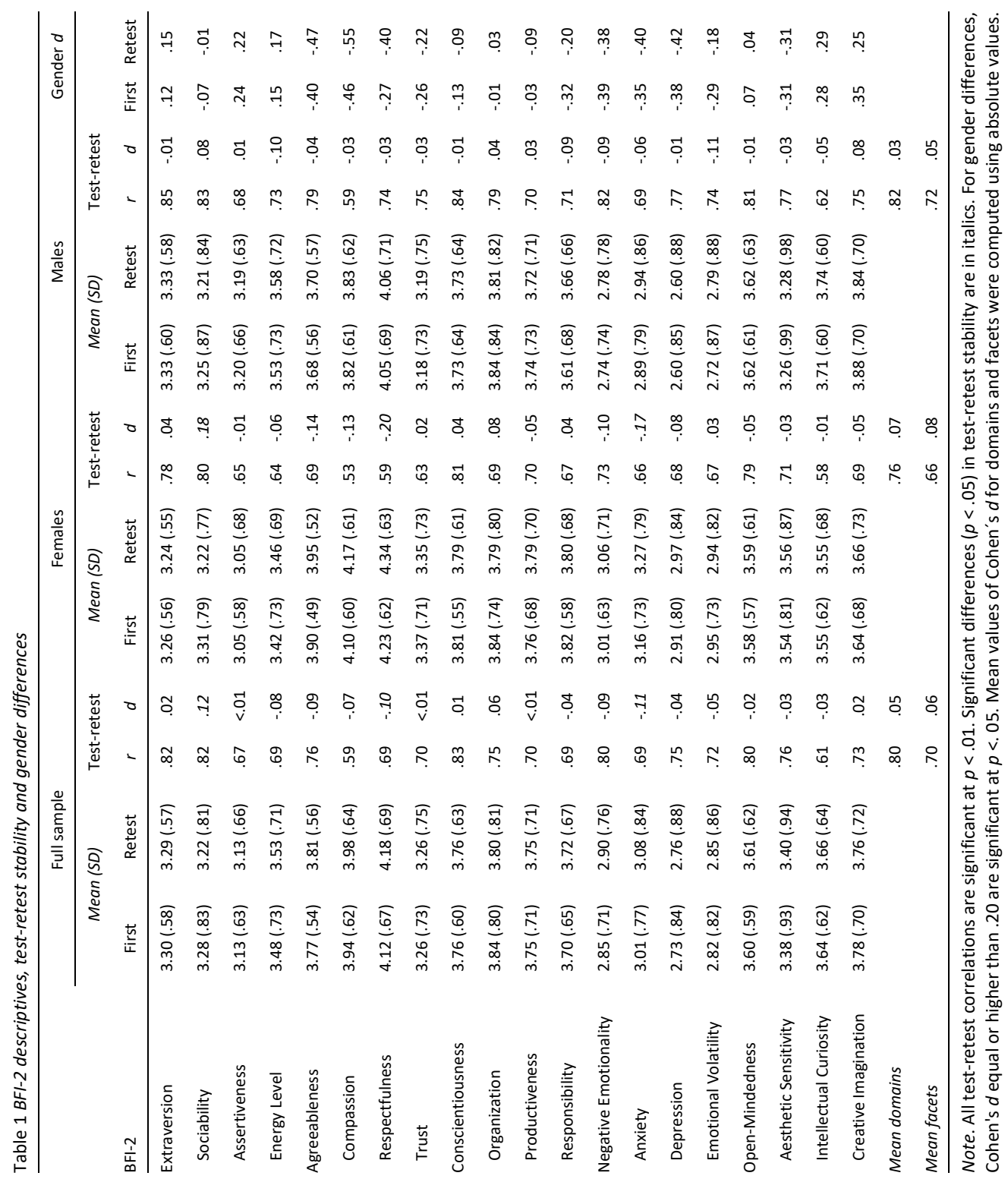


residuals vs. predicted values plot and Q-Q plot of standardized residuals; as suggested by Field, 2018). Results of these analyses are presented in Table 2, which also contains correlation coefficients between these variables. As seen in this Table, the BFI- 2 domains predicted $20 \%$ of variance in case of satisfaction with life, between 9 to $23 \%$ for psychological well-being $(M=16 \%)$, and 1 to $23 \%$ for behavioral self-report scales $(M=12 \%)$. These values are also comparable in facets, $22 \%$ in case of satisfaction with life, 9 to $24 \%$ for psychological well-being $(M=16 \%)$ and between 2 and $22 \%$ for behavioral self-reports $(M=12 \%)$.
To accomplish the last goal of our study explore the BFI-2's predictive power for various everyday behavior activities, we predicted each of 33 behaviors and activities by BFI-2 domains using the ordinal logistic regression and enter method. This method of analysis was used because the dependent variables (behaviors and activities) were measured on an ordinal level, as described in the method section. All models included gender and age to control. In Table 3, we report which behaviors were significantly predicted by each of the BFI-2 domains under $p<.01$ and .05 levels.

Table 2 The 6-months predictive power of BFI-2 for well-being and behavioral self-reports

\begin{tabular}{|c|c|c|c|c|c|c|c|c|}
\hline & $\begin{array}{c}\mathbf{E} \\
B(r)\end{array}$ & $\begin{array}{c}\text { A } \\
B(r)\end{array}$ & $\begin{array}{c}\text { C } \\
B(r)\end{array}$ & $\begin{array}{c}\mathbf{N} \\
B(r)\end{array}$ & $\begin{array}{c}0 \\
B(r)\end{array}$ & $\begin{array}{l}\Delta \text { adj. } R^{2} \\
\text { for BFI-2 } \\
\text { domains }\end{array}$ & $\begin{array}{c}\text { Strongest facet } \\
\text { predictors } \\
B(r)\end{array}$ & $\begin{array}{l}\Delta \text { adj. } R^{2} \\
\text { for facets }\end{array}$ \\
\hline SWLS & $.04(.26)$ & $.08(.23)$ & $.08(.25)$ & $-.38(-.46)$ & $-.05(.13)$ & .20 & $\begin{array}{l}\text { Depression }-.29(-.45) \text {, } \\
\text { Trust } .14(.27), \text { Anxiety - } \\
.15(-.41)\end{array}$ & .22 \\
\hline \multicolumn{9}{|c|}{ Psychological well-being } \\
\hline Autonomy & $.21(.36)$ & $-.10(.01)$ & $.09(.19)$ & $-.19(-.39)$ & $.06(.22)$ & .14 & $\begin{array}{l}\text { Depression }-.22(-.43) \text {, } \\
\text { Sociability } .17(.28), \\
\text { Organization } .13(.21)\end{array}$ & .15 \\
\hline $\begin{array}{l}\text { Environmental } \\
\text { mastery }\end{array}$ & $.10(.27)$ & $<.01(.07)$ & $.06(.17)$ & $-.18(-.36)$ & $.06(.20)$ & .09 & $\begin{array}{l}\text { Anxiety -.23(-.35), } \\
\text { Assertiveness .11(.24), } \\
\text { Companionship .11(.05) }\end{array}$ & .09 \\
\hline $\begin{array}{l}\text { Personal } \\
\text { growth }\end{array}$ & $.15(.36)$ & $.04(.11)$ & $.04(.19)$ & $-.17(-.41)$ & $.13(.30)$ & .15 & $\begin{array}{l}\text { Depression -.24(-.42), } \\
\text { Aesthetic Sensitivity } \\
.14(.11) \text {, } \\
\text { Energy Level .14(.34) }\end{array}$ & .15 \\
\hline $\begin{array}{l}\text { Positive } \\
\text { relations }\end{array}$ & $.15(.34)$ & $.23(.26)$ & $.03(.22)$ & $-.21(-.46)$ & $-.03(.22)$ & .20 & $\begin{array}{l}\text { Depression -.32(-.47), } \\
\text { Companionship .20(.19), } \\
\text { Trust .10(.23) }\end{array}$ & .21 \\
\hline Purpose in life & $.13(.31)$ & $.05(.13)$ & $.15(.25)$ & $-.11(-.37)$ & $.06(.24)$ & .13 & $\begin{array}{l}\text { Energy Level .15(.33), } \\
\text { Depression -.18(-.38), } \\
\text { Responsibility .16(.18) }\end{array}$ & .13 \\
\hline $\begin{array}{l}\text { Self- } \\
\text { acceptance }\end{array}$ & $.08(.34)$ & $.11(.26)$ & $.07(.27)$ & $-.33(-.50)$ & $.06(.26)$ & .23 & $\begin{array}{l}\text { Depression -.39(-.49), } \\
\text { Companionship .14(.18), } \\
\text { Responsibility .13(.23) }\end{array}$ & .24 \\
\hline
\end{tabular}


Table 2 continued

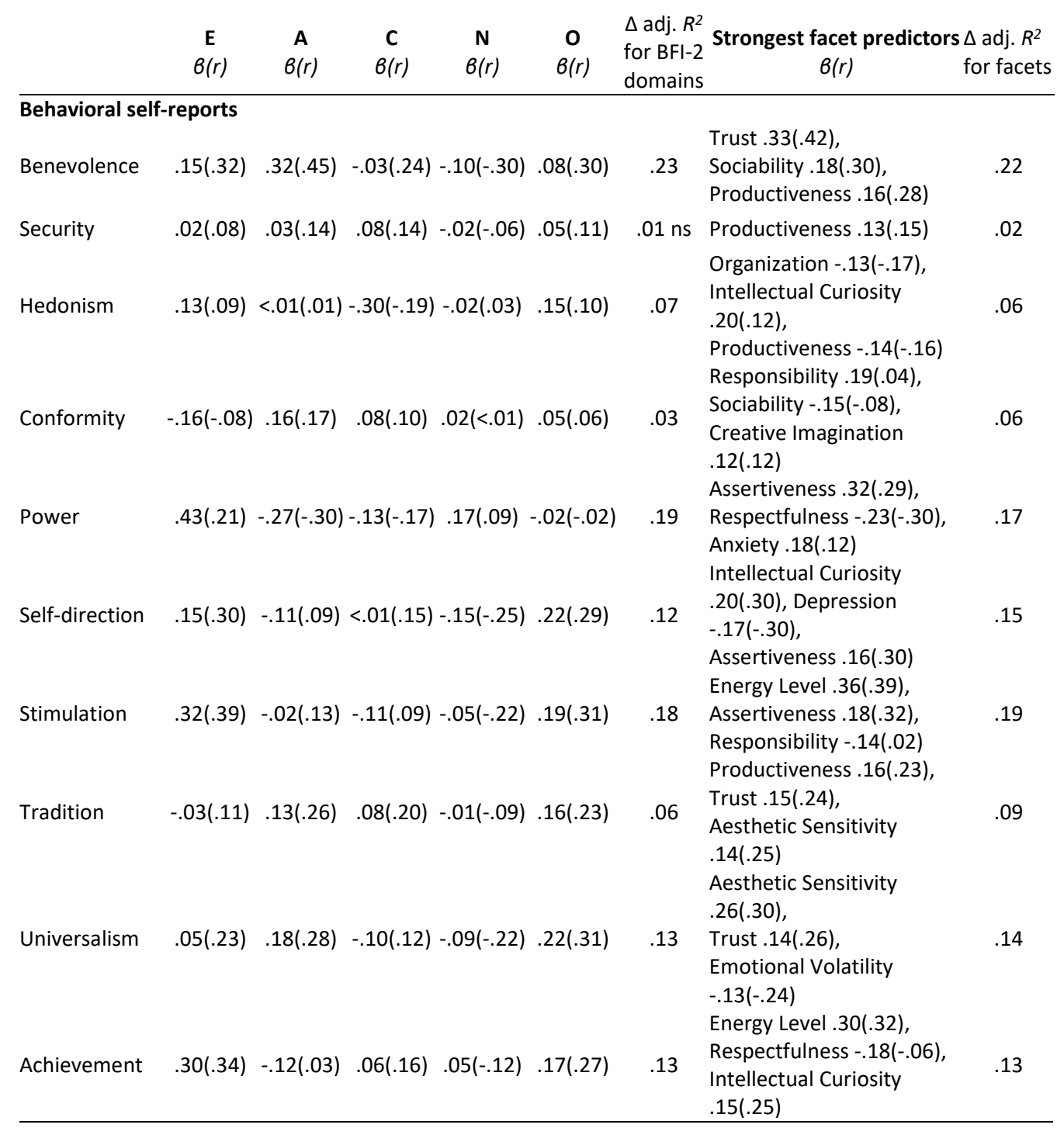

Note. For domain predictors, the absolute values of standardized Betas higher than .11 are significant at $p<0.05$. For facet predictors, the absolute values of standardized Betas higher than .10 are significant at $p<0.05$. The absolute values of correlations coefficients higher than .10 are significant at $p<0.05$. All regression models contained gender and age variables. $\Delta$ adj. $R^{2}$ for $\mathrm{BFI}-2$ domains - change of adjusted $R^{2}$ accounted for BFI-2 domains against model with age and gender, $\Delta$ adj. $R^{2}$ for facets - change of adjusted $R^{2}$ accounted for selected BFI-2 facets against model with age and gender. SWLS - Satisfaction With Life Scale; E - Extraversion, A - Agreeableness, C Conscientiousness, $\mathrm{N}$ - Negative Emotionality, O - Open-Mindedness. 
Table 3 Domain predictors of various behaviors and activities during the last 6 months

\begin{tabular}{|c|c|c|c|c|}
\hline Extraversion & Agreeableness & Conscientiousness & Negative Emotionality & Open-Mindedness \\
\hline \multicolumn{5}{|c|}{ For the last 6 months, how many times you have (been): } \\
\hline $\begin{array}{l}\text { Argued with } \\
\text { someone }(+/ 1.78)^{*}\end{array}$ & $\begin{array}{l}\text { Cleaned the household } \\
\text { thoroughly }(+/ 1.96)^{*}\end{array}$ & $\begin{array}{l}\text { Cleaned the household } \\
\text { thoroughly }(+/ 1.90)^{*}\end{array}$ & $\begin{array}{l}\text { Argued with someone } \\
(+/ 2.11)^{*}\end{array}$ & $\begin{array}{l}\text { Attended lecture } \\
(+/ 2.07)^{*}\end{array}$ \\
\hline Drunk $(+/ 1.99)^{*}$ & Cried $(+/ 2.17)^{*}$ & $\begin{array}{l}\text { Forgot something } \\
\text { important }(-/ 0.30)^{*}\end{array}$ & Cried $(+/ 3.00)^{*}$ & $\begin{array}{l}\text { Created some } \\
\text { artwork }(+/ 2.96)^{*} \\
\text { Daydreamed for }\end{array}$ \\
\hline $\begin{array}{l}\text { Forgot something } \\
\text { important }(+/ 1.74)^{*}\end{array}$ & Raving angry $(-/ 0.53)^{*}$ & $\begin{array}{l}\text { Late fore meeting } \\
(-/ 0.35)^{*}\end{array}$ & $\begin{array}{l}\text { Daydreamed for more } \\
\text { than hour }(+/ 1.79)^{*}\end{array}$ & $\begin{array}{l}\text { more than hour } \\
(+/ 1.74)^{*}\end{array}$ \\
\hline $\begin{array}{l}\text { Raving angry } \\
(+/ 2.87)^{*}\end{array}$ & & Slacked all day $(-/ 0.42)^{*}$ & $\begin{array}{l}\text { Forgot something } \\
\text { important }(+/ 1.96)^{*}\end{array}$ & $\begin{array}{l}\text { Earned extra cash } \\
(+/ 1.72)^{*}\end{array}$ \\
\hline $\begin{array}{l}\text { Singing in public } \\
(+/ 2.46)^{*}\end{array}$ & & Taken day-off $(-/ 0.45)^{*}$ & $\begin{array}{l}\text { Had nightmare or scary } \\
\text { dreams }(+/ 3.44)^{*}\end{array}$ & Hiking $(+/ 2.04)^{*}$ \\
\hline $\begin{array}{l}\text { Tried something } \\
\text { new }(+/ 1.71)^{*}\end{array}$ & & $\begin{array}{l}\text { Bought something just } \\
\text { for joy }(-/ 0.68)\end{array}$ & $\begin{array}{l}\text { Organized meeting with } \\
\text { friends }(-/ 0.62)^{*}\end{array}$ & Meditated $(+/ 2.32)^{*}$ \\
\hline $\begin{array}{l}\text { Visited sport event } \\
(+/ 2.02)^{*}\end{array}$ & & $\begin{array}{l}\text { Daydreamed for more } \\
\text { than hour }(-/ 0.69)\end{array}$ & Raving angry $(+/ 3.95)^{*}$ & $\begin{array}{l}\text { Organized meeting } \\
\text { with friends }(+/ 1.66)^{*}\end{array}$ \\
\hline $\begin{array}{l}\text { Bought something } \\
\text { just for joy }(+/ 1.57)\end{array}$ & & Drunk (-/0.62) & $\begin{array}{l}\text { Used calming meds } \\
(+/ 3.43)^{*}\end{array}$ & $\begin{array}{l}\text { Tried new meal or } \\
\text { drink }(+/ 1.75)^{*}\end{array}$ \\
\hline $\begin{array}{l}\text { Had nightmare or } \\
\text { scary dreams } \\
(-/ 1.52)\end{array}$ & & Singing in public $(-/ 0.54)$ & $\begin{array}{l}\text { Used meds for headache } \\
(+/ 2.16)^{*}\end{array}$ & $\begin{array}{l}\text { Tried something new } \\
(+/ 1.96)^{*}\end{array}$ \\
\hline Jogging $(+/ 1.68)$ & & $\begin{array}{l}\text { Tried new meal or drink } \\
(-/ 0.67)\end{array}$ & $\begin{array}{l}\text { Attended lecture } \\
(-/ 0.63)\end{array}$ & $\begin{array}{l}\text { Visited exhibition, } \\
\text { gallery }(+/ 2.48)^{*}\end{array}$ \\
\hline $\begin{array}{l}\text { Late fore meeting } \\
(+/ 1.81)\end{array}$ & & & $\begin{array}{l}\text { Bought something just } \\
\text { for joy }(+/ 1.42)\end{array}$ & $\begin{array}{l}\text { Visited theatre } \\
(+/ 4.15)^{*}\end{array}$ \\
\hline $\begin{array}{l}\text { Organized meeting } \\
\text { with friends }(+/ 1.64)\end{array}$ & & & $\begin{array}{l}\text { Cleaned the household } \\
\text { thoroughly }(+/ 1.40)\end{array}$ & $\begin{array}{l}\text { Used meds for } \\
\text { headache }(-/ 0.69)\end{array}$ \\
\hline \multirow[t]{4}{*}{$\begin{array}{l}\text { Tried new meal or } \\
\text { drink }(+/ 1.56)\end{array}$} & & & $\begin{array}{l}\text { Done adrenaline sports } \\
\text { (-/0.45) } \\
\text { Done sport activities } \\
(-/ 0.71)\end{array}$ & \\
\hline & & & $\begin{array}{l}\text { Done wellness, sauna, } \\
\text { etc. }(-/ 0.64)\end{array}$ & \\
\hline & & & Hiking $(-/ 0.65)$ & \\
\hline & & & $\begin{array}{l}\text { Travelled to new places } \\
(-/ 0.66)\end{array}$ & \\
\hline
\end{tabular}

Note. Behaviors and activities significantly predicted by domain are in domain columns, all of which are significant at $p<.05$ and marked * where $p<.01$. Positive correlation is indicated by + and negative by -.Values in brackets are for odds ratio of predictor in that column. All predictions were controlled for gender and age.

\section{Discussion}

The current study focused on 6-month test-retest stability and predictive power of the Slovak BFI-2. In relation to stability, we discovered high test-retest correlations for all domains and most of the facets. The highest test-retest stability was found for the Conscientiousness domain and the lowest for the Agreeableness domain, although all of these were .76 or higher. The stability for facets was generally slightly lower, the lowest was found for the Compassion facet, the highest for the 
Sociability facet and .70 in general. The good level of stability also holds for females and males separately. Our results confirmed the findings reported by Soto and John (2017) for 2-month stability of the original BFI-2 and suggested that the Slovak BFI-2 had good test-retest stability. Our results also contribute to the research of other sources of error in personality measures, such as the transient error or developmental changes (see Gnambs, 2014). The acceptable level of test-retest correlation after a 6-month period suggests that the $\mathrm{BFI}-2$ has good resistance to this kind of effect and can be a good option for research not only in studies with simple correlation design, but also for the studies using longitudinal approach.

Our next goal was to explore the predictive power of the Slovak BFI-2 focusing on 6-month predictions of well-being and behavioral measures. As expected, well-being measures were positively predicted by Extraversion and negatively by Negative Emotionality. These results clearly replicated the results of previous studies such those by Hicks and Mehta (2018), Reyes, Shmotkin, and Ryff (2002); however, the strong effect of Conscientiousness was not replicated in our study. Nevertheless, the effect of Extraversion and Negative Emotionality on well-being remains robust in our study. This effect has been recognized for a long time in personality research (e.g., Costa \& McCrae, 1980) and it is usually attributed to direct outcomes of these dispositions: positive affect and negative affect influencing broad range of well-being variables. The remaining three domains predicted only some well-being variables; however, all of them corresponded to the theoretical assumptions and previous findings (e.g., Anglim \& Grant, 2016) and displayed meaningful pattern of prediction. Open-Mindedness predicted personal growth, Agreeableness predicted positive relations and Conscientiousness pre- dicted purpose in life. As far as facets are concerned, Depression was the most frequent predictor of well-being variables, which, again, is meaningful because the items of this facet are strongly related to well-being.

The relationship between behavior connected to personal values and BFI-2 domains shows a meaningful pattern, too. The highest proportion of variance explained by $\mathrm{BFI}-2$ domains was identified in relation to benevolence - being kind to others, which was predicted mostly by Agreeableness. The second highest proportion explained by BFI2 domains was in power, reflecting the tendency of having control of others. This was mainly positively predicted by the Extraversion domain (especially facet Assertiveness), and negatively by Agreeableness (Respectfulness facet). Looking for stimulation was positively predicted by the domains of Extraversion and Open-Mindedness. Extraversion also positively predicted working really hard for achievement and negatively predicted behavior connected to conformity. In addition, Agreeableness also positively predicted conformity and universalism, as behavior focused on general goodness. Conscientiousness negatively predicted mainly hedonistic behavior. Although Negative Emotionality was not a notable predictor for behavioral measures, it positively predicted behavior focused on gaining power and negatively predicted self-direction. On the other hand, the Open-Mindedness domain also positively predicted self-direction, universalism, achievement and, quite surprisingly, even behavior focused on following tradition. With the exception of the last mentioned, these results are understandable and most of them are consistent with the results reported by Soto and John (2017), especially in relation to conformity, benevolence, power, hedonism and self-direction values. Differences might have been caused by the effect of culture, which is 
well-described in personality research (e.g., Church et al., 2008).

Our last goal was to explore the ecological validity of the Slovak BFI-2 by looking at the predictions of everyday behavior. Inspired by signature behaviors of Big Five domains reported by Chapman and Goldberg (2017), we selected 33 behavioral acts and asked participants about their approximate frequency in the last six months. This way, we tried to connect BFI-2 domains to the frequency of these various behaviors during the next 6 months. Results have shown interesting but expected patterns of these associations. Extraversion positively predicted behavior connected to sociability, assertiveness or social confidence and personal energy, such as singing in public, visiting a sport event or meeting with friends, being angry and arguing with someone or forgetting something important. Agreeableness predicted the lowest number of acts and it is connected positively to sensitive and caring behavior, such as cleaning household or crying and negatively to assertive or rough behavior, namely arguing. Conscientiousness negatively predicted disorganized or carefree behavior, such as forgetting important things, slacking or taking a day-off and positively predicted just thorough cleaning of the house. Negative Emotionality predicted the highest number of acts, positively connected mainly to the frequency of arguing and being angry, crying, daydreaming, forgetting important things, or using medications for calming or headache. It also negatively predicted organizing of social gatherings, relaxing or doing sports. Lastly, Open-Mindedness positively predicted exploring of the world, such as trying new things, hiking or learning and being creative. Overall, the results are consistent with the general definition of the individual traits and the theoretically expected behavior (Soto, John, 2017). However, our study not only confirmed that the Slovak BFI-2 had good predictive validity, but also contributed to many studies focused on the personality implications of everyday life (e.g., Mehl, Gosling, \& Pennebaker, 2006; Fleeson \& Gallagher, 2009). Our results confirmed the existence of meaningful trait-behavior links in Slovak environment and provided solid evidence for the relevance of Big Five personality traits in understanding everyday behavior.

\section{Limitations and Further Directions}

The main limitation of this study is the self-report nature of the behavioral measures. We did not use any advanced method of behavior measurement, such as daily diary or peer report, and our results could be biased by social desirability or other personal biases. Moreover, due to our effort to keep the length of the survey reasonably short, we used a limited number of behavioral self-report items. We did not fully report the results of these analyses or evaluated the power of prediction and we presented it in a shorter form, because the other option would have made the study inappropriately long and overfull. Finally, all our measures, with the exception of the BFI2 , were not psychometrically adapted in the Slovak context. As authors, we tried to carefully translate the items of these measures as well as critically evaluate the content validity; however, we have no further evidence regarding psychometric properties of the Slovak version of these instruments.

Future studies should focus on a broader range of daily behaviors connected to the Big Five factors in the Slovak context, which were not covered by this study. These studies should also overcome limitations related to possible self-report bias through alternative methods of behavior measurement such us diary studies, peer rating, automatic behavior recording, etc. 


\section{Conclusions}

The Slovak version of the Big Five Inventory 2 shows very good test-retest stability after 6 months both for full sample and each gender separately on domain and facet level. Regarding the predictive power, BFI-2 domains and facets show meaningful relationships with psychological well-being and life satisfaction, value-oriented behavior as well as with basic behavioral manifestations, which supports predictive and ecological validity of the Slovak BFI-2. Future studies should focus on further exploration of connections between $\mathrm{BFI}-2$ domains and facets and different mundane or "everyday" behavior and well-being in Slovakia using other than only self-report measures.

\section{Acknowledgements}

This work was supported by the Scientific Grant Agency VEGA [grant number 1/0363/18].

\section{Authors' ORCID}

Michal Kohút

https://orcid.org/0000-0002-4544-1331

Veronika Kohútová

https://orcid.org/0000-0002-9888-4275

Peter Žitný

https://orcid.org/0000-0002-7102-1197

Peter Halama

https://orcid.org/0000-0002-6938-4845

\section{References}

Balgiu, B. A. (2019). Satisfaction with life scale: New psychometric evidence in a Romanian emerging adults sample. The International Journal of $\mathrm{Hu}$ manities and Social Studies, 7(8), 184-190 . doi: 10.24940/theijhss/2019/v7/i8/HS1908-089
Bardi, A., \& Schwartz, S. H. (2003). Values and behavior: Strength and structure of relations. Personality and Social Psychology Bulletin, 29(10), 1207-1220. doi: 10.1177/0146167203254602

Chapman, B. P., \& Goldberg, L. R. (2017). Act-frequency signatures of the Big Five. Personality and Individual Differences, 116, 201-205. doi: 10.1016/j.paid.2017.04.049

Church, A. T., Katigbak, M. S., Reyes, J. A. S., Salanga, M. G. C., Miramontes, L. A., \& Adams, N. B. (2008). Prediction and cross-situational consistency of daily behavior across cultures: Testing trait and cultural psychology perspectives. Journal of Research in Personality, 42(5), 1199-1215.

Costa, P. T., \& McCrae, R. R. (1980). Influence of extraversion and neuroticism on subjective well-being: Happy and unhappy people. Journal of Personality and Social Psychology, 38(4), 668-678.

Danner, D., Rammstedt, B., Bluemke, M., Lechner, C., Berres, S., Knopf, T., Soto, C. J., \& John, O. P. (2019). Das Big-Five Inventar 2: Validierung eines Persönlichkeitsinventars zur Erfassung von 5 Persönlichkeitsdomänen und 15 Facetten [The Big Five Inventory-2: Validating a personality inventory to capture 5 personality domains and 15 facets]. Diagnostica, 65, 121-132 doi: 10.1026/0012-1924/a000218

Denissen, J. J. A., Geenen, R., Soto, C. J., John, O. P., \& van Aken, M. A. G. (2020). The Big Five Inventory-2: Replication of psychometric properties in a Dutch adaptation and first evidence for the discriminant predictive validity of the facet scales. Journal of Personality Assessment, 102(3), 309-324. https://doi.org/10.1080/0022 3891.2018.1539004

Diener, E., Emmons, R. A., Larsen, R. J., \& Griffin, S. (1985). The Satisfaction with Life Scale. Journal of Personality Assessment, 49(1), 71-75.

Field, A. P. (2018). Discovering statistics using IBM SPSS statistics. London: Sage.

Fleeson, W., \& Gallagher, P. (2009). The implications of Big Five standing for the distribution of trait manifestation in behavior: Fifteen experience-sampling studies and a meta-analysis. Journal of Personality and Social Psychology, 97(6), 1097-1114.

Fossati, A., Borroni, S., Marchione, D., Maffei, C. (2011). The Big Five Inventory (BFI): Reliability 
and validity of its Italian translation in three independent nonclinical samples. European Journal of Psychological Assessment, 27(1), 50-58. doi: 10.1027/1015-5759/a000043

Gnambs, T. (2014). A meta-analysis of dependability coefficients (test-retest reliabilities) for measures of the Big Five. Journal of Research in Personality. 52, 20-28. doi: 10.1016/j.jrp.2014.06.003

Halama, P., Kohút, M., Soto, C. J., John, O. P. (2020). Slovak adaptation of the Big Five Inventory (BFI2 ): Psychometric properties and initial validation. Studia Psychologica, 62(1), 74-87. https:// doi.org/10.31577/sp.2020.01.792

John, O. P., \& Srivastava, S. (1999). The Big-Five trait taxonomy: History, measurement, and theoretical perspectives. In L. A. Pervin \& O. P. John (Eds.), Handbook of personality: Theory and research (Vol. 2, pp. 102-138). New York: Guilford Press.

Mehl, M. R., Gosling, S. D., \& Pennebaker, J. W. (2006). Personality in its natural habitat: Manifestations and implicit folk theories of personality in daily life. Journal of Personality and Social Psychology, 90(5), 862-877.

Rammstedt, B., \& Danner, D. (2017). Die Facettenstructur des Big Five Inventory (BFI). Validierung für die deutsche Adaptation des BFI. Diagnostica, 63(1), 70-84. https://doi.org/10.1026/00121924/a000161

Ryff, C. D. (1989). Happiness is everything, or is it? Explorations on the meaning of psychological well-being. Journal of Personality and Social Psychology, 57(6), 1069-1081.

Ryff, C., Almeida, D. M., Ayanian, J. S., Carr, D. S., Cleary, P. D., Coe, C., ... \& Williams, D. (2010). National Survey of Midlife Development in the United States (MIDUS II), 2004-2006: Documentation of psychosocial constructs and composite variables in MIDUS II Project 1. Ann Arbor, MI: Inter University Consortium for Political and Social Research.

Schimack, U. S., Oishi, S., Furr, C. M., \& Funder, D. C. (2004). Personality and life satisfaction. A facet level analysis. Personality and Social Psychology Bulletin, 30(8), 1062-1075. doi: 10.1177/0146167204264292

Shchebetenko, S., Kalugin, A. Y., Mishkevich, A. M., Soto, C. J., \& John, O. P. (2020). Measurement invariance and sex and age differences of the Big Five Inventory-2: Evidence from the Russian version. Assessment, 27(3), 472-486. https://doi. org/10.1177/1073191119860901

Soto, C. J., \& John, O. P. (2017). The next Big Five Inventory (BFI-2): Developing and assessing a hierarchical model with 15 facets to enhance bandwidth, fidelity, and predictive power. Journal of Personality and Social Psychology, 113(1), 117-143. doi: 10.1037/pspp0000096

Stolarski, M., \& Matthews, G. (2016). Time perspectives predict mood states and satisfaction with life over and above personality. Current Psychology, 35(4), 516-526. doi: 10.1007/s12144016-9515-2 